\title{
RACISMO PRESENTE NA ANIMAÇÃO “SCRUB ME MAMA WITH A BOGGIE BEAT” DE WALTER LANTZ (1941)

\author{
Julio Geraldo Carvalho de Jesus ${ }^{1}$ \\ Davi Alexandre de Pistila Souza ${ }^{2}$ \\ Valéria Regina Zanetti ${ }^{3}$
}

\begin{abstract}
Resumo: As Animações são fontes interessantes de serem exploradas pela perspectiva histórica, uma vez que trazem questões impostas pelo contexto da produção e podem ser utilizadas como meio de transmitir conhecimentos e ideologias. O presente artigo faz uma reflexão acerca do tema do racismo nas animações dirigidas e produzidas por Walter Lantz, no ano de 1941, tomando como base o cartoon "Scrube Me Mama with a Boogie Beat", distribuído pela Universal Studios, e reexibido no ano de 1948. Apesar do racismo presente na obra, não há qualquer menção crítica ao filme, na época em que foi lançado, o que nos permitiu estabelecer um paralelo entre a animação de Lantz e a alegoria do açougue apresentada por Serguei Eisenstein no filme "A greve". No filme de Eisenstein, a cena final mostra um boi sendo degolado. A violência da cena causou grande impacto na população urbana, mas não impactou da mesma forma os habitantes da zona rural, acostumados com a prática. Da mesma forma, a obra de Lantz, permeada de traços racistas, não causou indignação na população negra, sobretudo por ser comum dentro da sociedade norte americana da época.
\end{abstract}

Palavras-chave: Cartoon; Racismo; Estereótipos; Negros; História; Walter Lantz.

\footnotetext{
${ }^{1}$ História/Universidade do Vale do Paraíba, Brasil. E-mail: juliogcj@hotmail.com.

2 Artes Visuais/Universidade do Vale do Paraíba, Brasil. E-mail: davipistila@gmail.com.

3 Docente/Universidade do Vale do Paraíba, Brasil. E-mail: vzanetti@univap.br.
} 